\title{
Outbreak
}

\section{Salmonella serotypes, resistance patterns, and food vehicles of salmonellosis in southern Brazil between 2007 and 2012}

\author{
Roberta Capalonga ${ }^{1}$, Rosane Campanher Ramos ${ }^{2}$, Jane Mari Correa Both², Mara Lúcia Tiba Soeiro², \\ Solange Mendes Longaray ${ }^{2}$, Simone Haas ${ }^{2}$, Eduardo Cesar Tondo ${ }^{1}$ \\ ${ }^{1}$ Department of Food Sciences, Laboratory of Microbiology and Food Control, Federal University of Rio Grande do \\ Sul, Institute of Food Science and Technology (ICTA/UFRGS), Porto Alegre, Rio Grande do Sul, Brazil \\ ${ }^{2}$ Foundation of Production and Health Research of Rio Grande do Sul, Central Laboratory of the Stare of Rio \\ Grande do Sul (FEEPS/IPB-LACEN/RS), Division of Product Analyses (DAP), Section of Microbiology, Porto \\ Alegre, Rio Grande do Sul, Brazil
}

\begin{abstract}
Introduction: Previous studies have identified Salmonella as the main causative agent of foodborne diseases in the state of Rio Grande do Sul (RS), southern Brazil, between 1997 and 2006. This study aimed to describe the Salmonella serotypes, antimicrobial patterns, and food vehicles of salmonellosis that occurred in RS between 2007 and 2012.

Methodology: Information about Salmonella isolates and salmonellosis outbreaks registered in the official records of the Central Laboratory of RS (FEEPS/IPB-LACEN/RS) was analyzed.

Results: Among the 163 isolates investigated, 138 (84.7\%) were identified as $S$. Enteritidis. The second and third most frequent serovars identified were $S$. Schwarzengrund (5.5\%) and $S$. Typhimurium (3.7\%). Homemade mayonnaise was the food vehicle most frequently identified (17.39\%), followed by pastry products $(15.94 \%)$ and beef $(12.32 \%)$. Antimicrobial resistance was analyzed; 12 drugs were tested. Higher percentages of resistance were observed to nitrofurantoin $(94.2 \%)$ and nalidixic acid (89.1\%). The resistance to these two drugs was verified in $80.43 \%$ of the isolates. Multi-resistance to three and five drugs was verified in four and two isolates, respectively.

Conclusions: Comparing the results of the present study with results of previous reports, it was possible to conclude that $S$. Enteritidis and homemade mayonnaise are still the main serotype and food vehicle of salmonellosis in RS and that antimicrobial resistance has been increasing among $S$. Enteritidis responsible for foodborne outbreaks in southern Brazil.
\end{abstract}

Key words: salmonellosis; Salmonella Enteritidis; antimicrobials; state of Rio Grande do Sul, Brazil

J Infect Dev Ctries 2014; 8(7):811-817. doi:10.3855/jidc.3791

(Received 14 May 2013 - Accepted 03 December 2013)

Copyright (C) 2014 Capalonga et al. This is an open-access article distributed under the Creative Commons Attribution License, which permits unrestricted use, distribution, and reproduction in any medium, provided the original work is properly cited.

\section{Introduction}

Salmonella is one of the main causative agents of foodborne disease (FBD) worldwide; it is responsible for serious health problems and significant economic losses [1-3]. In many countries, including in Brazil, foods of animal origin have been identified as the primary vehicles for human salmonellosis. In Brazil, meat, eggs, and egg products are the foods most frequently involved with illnesses [4-6]. Although there are more than 2,400 Salmonella serovars identified worldwide [7], in the last decade, a specific strain of $S$. Enteritidis was identified as the primary cause of salmonellosis in the state of Rio Grande do Sul (RS), the southernmost state of Brazil [8-11]. This strain was named $S$. Enteritidis SE86 and has been investigated by our group since 1997 to determine its effects on the public health of $\mathrm{RS}[5,6,8,9,12,13]$.
Among the investigations, antimicrobial resistance testing of the $S$. Enteriditis isolates has been done since 1999 [11,14,15]. Even though the salmonellosis caused by $S$. Enteritidis SE86 is usually limited to the gastrointestinal tract and treatment does not involve antibiotics, the use of these drugs is recommended when salmonellosis affects immunocompromised patients or when the symptoms of salmonellosis are more severe (e.g., fever and presence of blood in stools). Thus, the monitoring of the Salmonella serovars involved in foodborne diseases and their antimicrobial resistance patterns are of great importance to the control of salmonellosis and public health maintenance. This study aimed to investigate the main Salmonella serovars and their resistance patterns, as well as the food vehicles of salmonellosis that occurred in the RS between 2007 and 2012. 


\section{Methodology}

Source of data of Salmonella isolates

Data on Salmonella isolates and salmonellosis outbreaks investigated in the present study were taken from FEEPS/IPB-LACEN/RS. The official records, as well as the information on foodborne outbreaks from FEEPS/IPB-LACEN/RS, were analyzed and compiled by the technical staff of the Laboratory of Microbiology and Food Control of the Federal University of Rio Grande do Sul (ICTA/UFRGS). Records included information about all the samples collected from investigated salmonellosis cases in RS during the period of January 2007 to February 2012. The state of RS is one of 27 Brazilian states and has a population of approximately 10.7 million people, distributed in 496 cities. Salmonellosis outbreaks were noted and investigated by regional coordinators of the Division of Health Surveillance (DVS/RS), which, when possible, conducted sampling of suspect foods and transported them to FEEPS/IPB-LACEN/RS. In the laboratories of this institution, isolation and biochemical identification of Salmonella were carried out according to the methods described by the Compendium of Methods for the Microbiological Examination of Foods [16]. Isolates were serotyped at the Laboratory of Enterobacteriaceae at the National Reference Center for Intestinal Bacterial Infections, Oswaldo Cruz Foundation (FIOCRUZ) (Rio de Janeiro, Brazil) following methods described by Kauffman [17]. Official reports containing information about pathogenic microorganisms and foodborne outbreaks were prepared by FIOCRUZ and remitted to FEEPS/IPB-LACEN/RS. These documents were analyzed, and the information about 163 isolates of Salmonella were investigated in the present study.

\section{Antimicrobial susceptibility}

Antimicrobial susceptibility testing was performed at FIOCRUZ. The isolates were analyzed for susceptibility to 12 antimicrobials using the disk diffusion method, according to the guidelines of the Clinical Laboratory Standards Institute [18]. The antimicrobial agents tested were ampicillin (AMP), chloramphenicol (CHL), tetracycline (TCY), cefoxitin (FOX), ceftazidime (CAZ), streptomycin (STR), ciprofloxacin (CIP), gentamicin (GEN), imipenem (IMP), nalidixic acid (NAL), trimethoprim/sulfamethoxazole (STX), and nitrofurantoin (NIT). The resistance profile was determined according to the standards used by Laboratory of Enterobacteriaceae at FIOCRUZ.

\section{Results}

Among the 163 isolates analyzed, 138 (84.7\%) were identified as $S$. Enteritidis, $9(5.5 \%)$ as $S$. Schwarzengrund, and $6(3.7 \%)$ as $S$. Typhimurium. Six other serovars were identified, each one found in only one food sample (Table 1).

As shown in Table 2, among the foods involved in salmonellosis caused by $S$. Enteritidis in the state of RS between 2007 and 2012, homemade mayonnaise was the most frequently identified food vehicle $(17.39 \%)$, followed by pastry products $(15.94 \%)$ and beef $(12.32 \%)$. S. Enteritidis was isolated in $9.42 \%$ of processed meat samples, $6.52 \%$ of chicken meat samples, and $2.17 \%$ of pork samples. Other serovars of Salmonella were also isolated: $S$. Derby from processed meat, $S$. Infantis from sandwiches, $S$. London from processed meat, $S$. Panama from processed meat, $S$. Give from processed meat, $S$. Typhimurium from mayonnaise and processed meat, $S$. Schwarzengrud from rice, pasta, meats, mayonnaise and raw vegetables, $S$. Agona from processed meat, and $S$. enterica from pastry products, meat, and eggs (data not shown).

\section{Antimicrobial resistance}

Antimicrobial resistance patterns were investigated only in $S$. Enteritidis isolates; the results are presented in Table 3. The highest resistance percentage was observed for NIT $(94.2 \%)$ and NAL (89.1\%). Only two isolates were resistant to TCY, two to AMP, and two to FOX. Three isolates were resistant to CAZ, CIP, and SXT, separately, while no isolate showed resistance to CHL, STR, IMP, and GEN. Table 4 shows the resistance profiles of the $S$. Enteritidis isolates. Among them, $11.6 \%$ were resistant to only one drug (NIT or NAL) and $80.43 \%$ were resistant to two antibiotics (NAL and NIT). Only one isolate was resistant to NAL and TCY. Three isolates showed intermediate resistance to NIT and one to STR. One isolate was multi-resistant to NAL, NIT, and SXT. Three isolates were multi-resistant to NAL, NIT, and TCY. Two isolates demonstrated multi-resistance to NAL, NIT, AMP, FOX, and CIP, while another isolate was multi-resistant to NAL, NIT, AMP, FOX, and CAZ. 
Table 1. Salmonella serovars involved in foodborne outbreaks in the state of Rio Grande do Sul, Brazil, between 2007 and 2012

\begin{tabular}{ccc}
\hline Salmonella serovars & Number of involved food samples & Percentage (\%) \\
\hline S. Enteritidis & 138 & 84.7 \\
S. Schwarzengrund & 9 & 5.5 \\
S. Typhimurium & 6 & 3.7 \\
S. enterica & 4 & 2.5 \\
S. Infantis & 1 & 0.6 \\
S. Agona & 1 & 0.6 \\
S. Derby & 1 & 0.6 \\
S. London & 1 & 0.6 \\
S. Give & 1 & 0.6 \\
S. Panama & 1 & 0.6 \\
Total & $\mathbf{1 6 3}$ & $\mathbf{1 0 0}$ \\
\hline
\end{tabular}

Table 2. Foods involved in salmonellosis outbreaks caused by $S$. Enteritidis in the state of Rio Grande do Sul, Brazil, between 2007 and 2012

\begin{tabular}{|c|c|c|}
\hline Food & Number of positive samples & Percentage $(\%)$ \\
\hline Homemade mayonnaise & 24 & 17.39 \\
\hline Pastry products (pies, cakes, puddings, sweets, others) & 22 & 15.94 \\
\hline Processed meat (ham, sausage, mortadella, etc.) & 13 & 9.42 \\
\hline Mixed food (pasta with sauce, rice with meat, etc.) & 11 & 7.97 \\
\hline Sandwiches ( 7 hamburgers, 1 stuffed fried bread dough) & 8 & 5.80 \\
\hline Cheese & 6 & 4.35 \\
\hline Raw egg & 5 & 3.62 \\
\hline Rice & 5 & 3.62 \\
\hline Boiled vegetables ( 2 potatoes, 2 canned mixed vegetables) & 4 & 2.90 \\
\hline Raw capelletti & 2 & 1.45 \\
\hline Fruit salad & 1 & 0.72 \\
\hline Eggs threads & 1 & 0.72 \\
\hline Cold chicken pie & 1 & 0.72 \\
\hline Peas & 1 & 0.72 \\
\hline Potato chips & 1 & 0.72 \\
\hline Total & 138 & 100 \\
\hline
\end{tabular}


Table 3. Antimicrobial results of $S$. Enteritidis involved in foodborne salmonellosis in the state of Rio Grande do Sul, Brazil, between 2007 and 2012

\begin{tabular}{ccc}
\hline Antimicrobials & Number of resistant isolates & Percentage (\%) \\
\hline NIT & 130 & 94.2 \\
NAL & 123 & 89.1 \\
TCY & 2 & 1.4 \\
AMP & 2 & 1.4 \\
FOX & 2 & 1.4 \\
CAZ & 1 & 0.7 \\
CIP & 1 & 0.7 \\
SXT & 1 & 0,7 \\
CHL & 0 & 0 \\
STR & 0 & 0 \\
IMP & 0 & 0 \\
GEN & 0 & 0 \\
NIT* & 3 & 2,2 \\
STR* & 1 & 0,7 \\
\hline
\end{tabular}

AMP: ampicillin, CHL: chloramphenicol, TCY: tetracycline, FOX: cefoxitin, CAZ: ceftazidima, STR: streptomycin, CIP: ciprofloxacin, GEN: gentamicin, IMP: imipenem, NAL: nalidixic acid, STX: trimethoprim/sulfamethoxazole, NIT: nitrofurantoin

*Intermediate resistance

Table 4. Antimicrobial resistance profiles of $S$. Enteritidis involved in salmonellosis in the state of Rio Grande do Sul, Brazil, between 2007 and 2012

\begin{tabular}{cc}
\hline Antimicrobial profile & Number of isolates \\
\hline NIT & 12 \\
NAL & 4 \\
NAL, NIT & 111 \\
NAL, TCY & 1 \\
NAL, NIT, SXT & 1 \\
NAL, NIT, TCY & 3 \\
NAL, NIT, AMP, FOX, CIP & 2 \\
NAL, NIT, AMP, FOX, CAZ & 1 \\
NIT* & 2 \\
\hline STR* & 1 \\
\hline
\end{tabular}

AMP: ampicillin, CHL: chloramphenicol, TCY: tetracycline, FOX: cefoxitin, CAZ: ceftazidima, STR: streptomycin, CIP: ciprofloxacin, GEN: gentamicin, IMP: imipenem, NAL: nalidixic acid, STX: trimethoprim/sulfamethoxazole, NIT: nitrofurantoin

*Intermediate resistance

\section{Discussion}

Based on the results of the present study, $S$. Enteritidis was the predominant Salmonella serovar isolated from foods involved in salmonellosis in RS between 2007 and 2012. This result is similar to the results of previous studies analyzing foods involved in salmonellosis outbreaks that occurred in RS. Geimba et al. [12] demonstrated that $97 \%$ of foods involved in salmonellosis that occurred between 1999 and 2000 in the state of RS presented $S$. Enteritidis. Likewise, de Oliveira et al. [8] indicated that this serovar was found in $93 \%$ of foods involved in salmonellosis that occurred in RS between 2001 and 2002. De Paula et al. [11] demonstrated that $87 \%$ of foods responsible for salmonellosis in RS between 2003 and 2006 were identified as $S$. Enteritidis. These results demonstrate that $S$. Enteritidis has been the main serovar isolated from foods involved in foodborne salmonellosis in the state of RS between 1999 and 2012.

Isolates of $S$. Enteritidis were also identified as major food pathogens in other states of Brazil such as Santa Catarina [19], Paraná [20,21], and São Paulo [22]. Recently, the same serovar was also identified as the main causative agent of human salmonellosis in other countries such as the United States [23] and China [24].

In the present study, homemade mayonnaise was identified as the food most frequently involved in foodborne salmonellosis in RS between 2007 and 2012. Similar results were shown by Costalunga \& Tondo [5] and Silveira \& Tondo [6] during their investigations of salmonellosis that occurred between 1997 and 1999 and between 2000 and 2001 in RS, respectively. 
According to the Centers for Disease Control and Prevention (CDC) [25], egg was the food most involved in salmonellosis outbreaks in the United States in 2007. Eggs have been primarily responsible for salmonellosis elsewhere in the world $[1,2,26]$. According to the CDC [27], only one in ten thousand eggs are contaminated with Salmonella in the United States. It is possible that a similar proportion of contaminated eggs could be found in Brazil, considering the well-controlled industrialized egg production in Brazil. However, uninspected eggs may have much higher percentages of Salmonella contamination. The use of uninspected raw eggs was identified as one of the main causative factors of salmonellosis in the last decade in RS $[5,6,12,13]$, even though the use of raw eggs is not allowed by the current good manufacturing practices regulations of RS [28].

As shown in Table 2, pastry products and beef were the second and third main food vehicles of $S$. Enteritidis in the state of RS. These results can be justified by the extensive handling of pastry products during their preparation, as well as the possible crosscontamination within food services that prepare beef meals. The facts that $S$. Enteritidis has been associated mainly with poultry meat [13] and, based on the results of the present study, $S$. Enteritidis was found on roast and baked beef, strongly suggest the occurrence of cross-contamination after the heat processing of these preparations. The hypothesis that one of the main causative factors of salmonellosis in RS between 2007 and 2012 was the cross-contamination after thermal processing is reinforced by the isolation of $S$. Enteritidis from foods such as ham, mortadella, pasta with meat sauce, and rice with meat.

The 138 strains of $S$. Enteritidis isolated from food involved in foodborne outbreaks were analyzed for susceptibility to antimicrobial agents (Table 3 ). The highest percentages of resistance were observed for NIT and NAL.

Antimicrobial resistance is increasing rapidly worldwide, and the indiscriminate use and misuse of antibiotics has facilitated the emergence of resistance in many Salmonella serovars [13]. Although antimicrobial resistance in $S$. Enteritidis has been considered low when compared with the dramatic resistance increase of some isolates of $S$. Typhimurium [29], attention should be paid to the frequent isolation of $S$. Enteritidis resistant to one or more antibiotics. The increasing antimicrobial resistance surveillance of $S$. Enteritidis is especially important since this serovar became the predominant agent of human salmonellosis
Figure 1. Increase in the percentage of $S$. Enteritidis strains resistant to nalidixic acid (NAL) isolated from foods involved in outbreaks in the state of Rio Grande do Sul, Brazil, between 1999 and 2012. Source: Geimba et al. (2005); Oliveira et al. (2006); De Paula et al. (2011) and present results from this study.

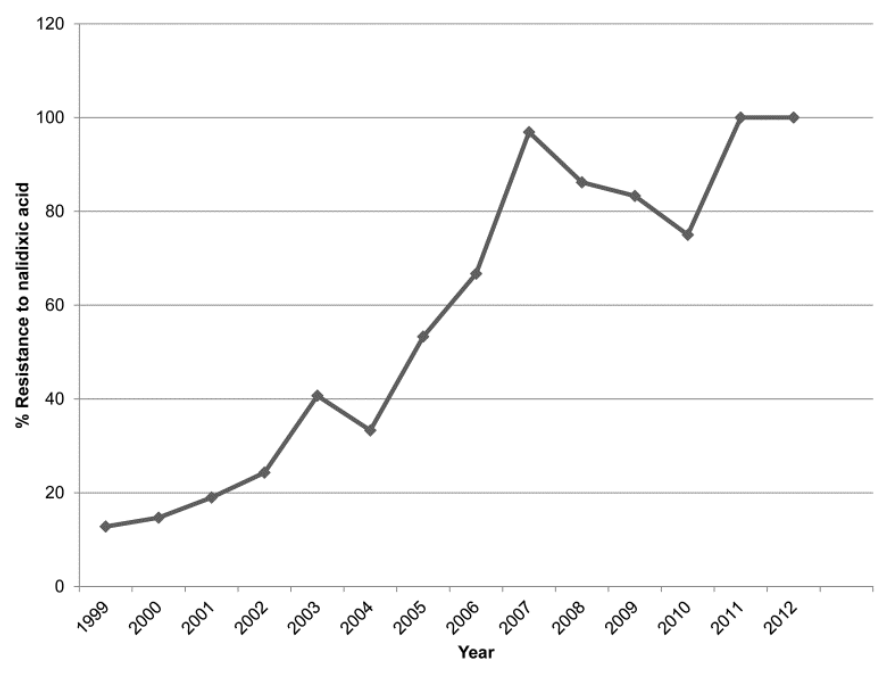

in many countries in recent years, including Brazil. During the last decade, in RS, the resistance of $S$. Enteritidis isolated from foodborne illnesses has been the subject of several studies [8,11,13-15]. Several drugs have been analyzed, and the $S$. Enteritidis responsible for salmonellosis in RS showed an increased resistance to AMP and especially to NAL [3,11]. Between the years 1999 and 2006, S. Enteritidis isolates showed a gradual increase in resistance to NAL $[8,11,14]$. If these results are put together with the results of the present study, one can observe a clear growing increase in the proportion of $S$. Enteritidis isolates resistant to NAL (Figure 1).

Geimba et al. [14] observed that in 1999, 12.8\% of the $S$. Enteritidis isolates were resistant to NAL; in 2000 , this percentage rose to $14.7 \%$. De Oliveira et al. [8] found an increase in the resistance to the same antibiotic, from $19.0 \%$ to $24.3 \%$ between 2001 and 2002. De Paula et al. [11] found an increase from $40.7 \%$ to $66.7 \%$ from 2003 to 2006 . As demonstrated in the present study, in $2007,89.1 \%$ of the isolates were resistant to nalidixic acid, increasing to $100 \%$ in 2012.

Geimba et al. [14] analyzed isolates of $S$. Enteritidis involved in foodborne outbreaks in RS between 1999 and 2000 and found that $94.6 \%$ of isolates were sensitive to kanamycin, $95.9 \%$ to trimethoprim/sulfamethoxazole, $\quad 98.6 \%$ to chloramphenicol, and $97.3 \%$ to sulphazotrim. However, de Oliveira et al. [8] analyzed isolates of $S$. Enteritidis involved in salmonellosis outbreaks in RS 
between 2001 and 2002 and found the highest percentage of sensitivity to tetracycline $(91.1 \%)$ and chloramphenicol (98.7\%) These authors did not detect resistance to trimethoprim/sulfamethoxazole or sulphazotrim. In 2005, Geimba et al. [14] reported that between 1999 and 2000, the highest intermediate resistance was to streptomycin (37\%), gentamicin (13.7\%), and nalidixic acid (13.7\%) among $S$. Enteritidis isolated from foods involved in salmonellosis in RS. De Oliveira et al. [8] showed that kanamycin (29.1\%), neomycin (17.7\%), and streptomycin $(13.9 \%)$ had the greatest intermediate resistance in isolates of $S$. Enteritidis involved in foodborne outbreaks between 2001 and 2002. In the present study, however, intermediate resistance was found at low levels to nitrofurantoin $(2.2 \%)$ and streptomycin $(0.7 \%)$.

In Denmark, a study of the period from 1995 to 2000 examined 2,546 S. Enteritidis isolates. This study demonstrated that 82 isolates $(3.2 \%)$ were resistant to nalidixic acid [30]. Prior to this study, Breuil et al. [31] found lower percentages of resistance to nalidixic acid (2\% to $4 \%$ ) in $S$. Enteritidis isolated from human and animal samples in France between 1994 and 1997.

The indiscriminate use of antibiotics, especially quinolones, in poultry facilitated the spreading of positive lots for $S$. Enteritidis [32]. The resistance to quinolones by $S$. Enteritidis was motivated by the extensive use of quinolones and similar drugs in animal feed [32]. Several studies have reported that Salmonella - mainly from poultry - has emerged as particularly resistant to quinolones $[31,33,34]$. This increasing Salmonella antimicrobial resistance in different parts of the world may indicate a spread of resistant or multi-resistant epidemic strains [35]. This is important because food from animal origins, especially eggs and meat products, are frequently involved in salmonellosis outbreaks. One must consider that Brazil is the largest exporter of chicken and beef meat in the world and that many meat industries are located in the southern region of the country. The evaluation of the resistance in Salmonella isolates, therefore, is of great importance.

In conclusion, the results of the present study demonstrated that $S$. Enteritidis was the serovar most frequently isolated from foods involved in salmonellosis in RS between 2007 and 2012. Thus, it can be concluded that this serovar was the major agent of foodborne illnesses in the state of RS in recent years. Furthermore, during the last decade, there was an increase in the resistance of $S$. Enteritidis isolates to nalidixic acid. The results of this study also demonstrated that homemade mayonnaise was the main food vehicle of salmonellosis in RS. Therefore, continuous monitoring of main causative bacterial agents of foodborne diseases in RS is important in order to investigate changes in these strains and to prevent new and future foodborne outbreaks.

\section{Acknowledgements}

The authors wish to thank all the Sanitary Surveillance Officers and FEPPS/IPB/LACEN, who have worked hard to improve the food safety of the state of Rio Grande do Sul. Special thanks to the Director of FEPPS/IBP/LACEN, Dra. Raquel Fiori de Souza, for her intense dedication to the public health of the state of Rio Grande do Sul and for her important contribution to this study.

\section{References}

1. Hughes C, Gillespie IA, O'Brien SJ, The Breakdowns in Food Safety Group (2007) Foodborne transmission of infectious intestinal disease in England and Wales, 19922003. Food Control 18: 766-772.

2. Greig JD, Ravel A (2009) Analysis of foodborne outbreak data reported internationally for source attribution. Int J Food Microbiol 130: 77-87.

3. de Oliveira FA, Pasqualotto AP, Da Silva WP, Tondo EC (2010) Characterization of Salmonella Enteritidis isolated from human samples. Food Res Intl 45: 1000-1003.

4. Brasil Ministério da Saúde. Secretaria de Vigilância em Saúde (2010) Manual Integrado de Prevenção e Controle de Doenças Transmitidas por Alimentos. Available: http://portal.saude.gov.br/portal/arquivos/pdf/manual_dta.pdf. Acessed 12 August 2012.

5. Costalunga S, Tondo EC (2002) Salmonelloses in Rio Grande do Sul, 1997 a 1999. Brazilian Journal of Microbiology 33: 342-346.

6. Silveira JB, Tondo EC (2006) Salmonelloses outbreaks occured in Rio Grande do Sul, Southern Brazil, during 2000 to 2001. In: International Symposium Salmonella and salmonellosis. Epidemiology and Public Health. Saint Malo, France, Sessão 5, Editora: Pierre Colin e Geneviève Clément 521-522.

7. Heyndrickx M, Vandekerchove D, Herman L, Rollier I, Grijspeerdt K, De Zut L (2005) Recent changes in Salmonella nomenclature: the need for clarification. Vet J 170: 275-277.

8. de Oliveira FA, Brandeli A, Tondo EC (2006) Antimicrobial resistance in Salmonella Enteritidis from foods involved in human salmonellosis outbreaks in southern Brazil. New Microbiol 29: 49-54.

9. Malheiros PS, De Paula CMD, Tondo EC (2007) Growth kinetics of Salmonella Enteritidis involved in outbreaks of foodborne illness in Rio Grande do Sul, southern Brazil: a comparison with other serovar strains. Ciência e Tecnologia de Alimentos 27: 751-755.

10. Welker CAD, Both JMC, Longaray SM, Haas S, Soeiro MLT, Ramos RC (2010) Análise microbiológica dos alimentos envolvidos em surtos de doenças transmitidas por alimentos (DTA) ocorridos no estado do Rio Grande do Sul, Brasil. Rev Bras Bioci, Porto Alegre 8: 44-48.

11. De Paula CMD, Ritter AC, Pieta L, Do Amaral PH, Tondo EC (2011) Antimicrobial resistance in Salmonella enteritidis from foods involved in human salmonellosis outbreaks in 
southern Brazil from 2003 to 2006. J Microbiol Antimicrob 3: 233-240.

12. Geimba MP, Tondo EC, de Oliveira FA, Canal CW, Brandelli A (2004) Serological characterization and prevalence of spvR genes in Salmonella isolated from foods involved in outbreaks in Brazil. J Food Prot 67: 1229-1233.

13. Tondo EC and Ritter AC (2012) Salmonella and Salmonellosis in Southern Brazil: a review of the last decade Salmonella: Classification, Genetics and disease Outbreaks, First edition, New York:Nova Science Publishers 267 p.

14. Geimba MP, Tondo EC, Brandelli A (2005) Antimicrobial Resistance in Salmonella Enteritidis Isolated from Foods Involved in Human Foodborne Outbreaks Occurred in the South of Brazil, 1999 - 2000. J Food Saf 25: 173-182.

15. de Oliveira FA, Frazzon APG, Brandeli A, Tondo EC (2007) Use of PCR-ribotyping, RAPD, and antimicrobial resistance for typing of Salmonella enteritidis involved in food-borne outbreaks in Southern Brazil. J Infect Dev Cries 1: 170-176.

16. Downes FP and Ito K, editors (2001) Compendium of Methods for the Microbiological Examination of Foods, 4th edition. Washington: American Public Health Association.

17. Kauffman F (1972) Kauffmann-White Schema. In: Serological diagnosis of Salmonella species. Copenhagen: Munksgaard. 59-123.

18. Clinical and Laboratory Standards Institute (2010) Performance Standards for Antimicrobial Susceptibility Testing; Twentieth Informational Supplement. M100-S20 30(1) CLSI: Wayne, PA, USA.

19. Koerich GMD, De Luca ANB, Philippi JMS, Da Rosa CMA (2010) Análise dos surtos de DTA causados por Salmonella sp em Santa Catarina, Brasil, de 2006 a 2008. D. Ciências da Saúde - 3. Saúde Coletiva - 4. Saúde Pública. 62ª Reunião Anual da SBPC. Available: http://www.sbpcnet.org.br/livro/62ra/resumos/resumos/1078. htm. Acessed 12 August 2012.

20. Alcocer I, de Oliveira KMP, Vidotto MC, Oliveira TCRM (2006) Discrimination of Salmonella serovars isolated from chicken meat by REP and ERIC-PCR and phagotyping of Enteriditis serovars. Ciência e Tecnologia de Alimentos 26: 414-420.

21. Kottwitz LBM, Back A, Leão JA, Alcocer I, Karan M, Oliveira TCRM (2008) Contaminação por Salmonella spp. em uma cadeia de produção de ovos de uma integração de postura comercial. Arq Bras Med Vet Zootec 60: 496-498.

22. Tavechio AT, Ghilardi ÂCR, Peresi JTM, Fuzihara TO, Yonamine EK, Jakabi M, Fernandes SA (2002) Salmonella serotypes isolated from nonhuman sources in São Paulo, Brazil, from 1996 through 2000. J Food Prot 65: 1041-1044.

23. Cho S, Whittam TS, Boxrud DJ, Bartkus JM, Rankin SC, Wilkins MJ, Somsel P, Downes FP, Musser KA, Root TP, Warnick LD, Wiedmann M, Saeed AM (2010) Use of multiple-locus variable number tandem repeat analysis and phage typing for subtyping of Salmonella Enteritidis from sporadic human cases in the United States. J Appl Microbiol 108: 859-867.

24. He G-Z, Feng Y, Tian W-I, Qian N, Deng S-X, An C-W (2011) Populations of Salmonella Enteritidis in Orally Infected White Chinese Goose. Journal of Animal and Veterinary Advances 10: 2234-2239.

25. Centers for Disease Control and Prevention (2009) FoodNet 2007 Surveillance Report. Atlanta: U.S. Department of Health and Human Services. Available:
http://www.cdc.gov/foodnet/PDFs/2007 annual_report_508.p df. Acessed 12 August 2012.

26. Much P, Pichler J, Allerberger F (2007) Foodborne infectious outbreaks, Austria 2005. Wien Klin Wochenschr 119: 150157.

27. Centers for Disease Control and Prevention (2004) Salmonella surveillance: Annual Summary, 2004. CDC: Atlanta, GA, USA.

28. RIO GRANDE DO SUL (2009) Portaria SES/RS nº. 78, de 30 de janeiro de 2009. Aprova a Lista de Verificação em Boas Práticas para Serviços de Alimentação, aprova Normas para Cursos de Capacitação em Boas Práticas para Serviços de Alimentação e dá outras providências. Diário Oficial do Estado do Rio Grande do Sul. Secretaria da Saúde, Porto Alegre, RS. $1^{\text {a }}$ Edição, p. 35-40. Available: http://www.saude.rs.gov.br/upload/1365096500 portaria\%20 78_09.pdf. Acessed 12 August 2012.

29. Yang SJ, Park KY, Kim SH, No KM, Besser TE, Yoo HS, Kim SH, Lee BK, Park YH (2002) Antimicrobial resistance in Salmonella enterica serovars Enteritidis and Typhimurium isolated from animals in Korea: comparison of phenotypic and genotypic resistance characterization. Vet Microbiol 86: 295-301.

30. Molbak K, Gerner-Smidt P, Wegener HC (2002) Increasing Quinolone Resistance in Salmonella enterica Serotype Enteritidis. Emerg Infect Dis 8: 514-515.

31. Breuil J, Brisabois A, Casin I, Armand-Lefèvre L, Frémy S, Collatz E (2000) Antibiotic resistance in salmonellae isolated from humans and animals in France: comparative data from 1994 and 1997. J Antimicrob Chemother 46: 965-971.

32. Silva EN, Duarte A (2002) Salmonella Enteritidis em aves: retrospectiva no Brasil. Revista Brasileira de Ciência Avícola 2: $85-100$.

33. Malorny B, Schoroeter A, Helmuth R (199) Incidence of quinolone resistance over the period 1986 to 1998 in veterinary Salmonella isolates from Germany. Antimicrob Agents Chemother 43: 2278-2282.

34. Hakanen A, Siitonen A, Kotilainen P, Huovinen P (1999) Increasing quinolone resistance in salmonella isolates of foreign origin in Finland. In: Program and Abstracts of the Thirty-Ninth Interscience Conference on Antimicrobial Agents and Chemotherapy, San Francisco, CA, 1999. Abstract 7515, p. 100. American Society for Microbiology, Washington, DC, USA.

35. Cruchaga S, Echeita A, Aludea A, Garcia-Pena J, Frias N, Usera MA (2001) Antimicrobial resistance in salmonellae from humans, food and animals in Spain in 1998. J Antimicrob Chemother 47: 315-321.

\section{Corresponding author}

Eduardo César Tondo

Department of Food Sciences, Laboratory of Microbiology and Food Control, Federal University of Rio Grande do Sul, Institute of Food Science and Technology (ICTA/UFRGS), Porto Alegre, Rio Grande do Sul, Av. Bento Gonçalves, 9500, prédio 43212, Sala 205, Campus do Vale, Agronomia, Porto Alegre, RS, Brazil Zip Code: 91501-970

Phone: 005551 3308-6677

Email: tondo@ufrgs.br

Conflict of interests: No conflict of interests is declared. 